
Санкт-Петербургский государственный университет

DOI : $10.14746 /$ ps.2018.1.17

(Sankt-Petersburg State University)

https://orcid.org/0000-0001-8063-2558

\author{
Александр ШИРИНЯНЦ (Aleksandr SHIRINYANTS) \\ Московский государственный университет имени М. В. Ломоносова \\ (Lomonosov Moscow State University) \\ https://orcid.org/0000-0002-6949-2256
}

\title{
ТЕРРОРИЗМ И РЕВОЛЮЦИЯ
}

«Царство террора» - одно из наиболее распространенных словесных клише - в настоящее время прочно ассоциируется в исторической памяти с традицией Французской и Октябрьской революций; оно часто рассматривается как эквивалент нового революционного государства, пришедшего на смену старому порядку. Не в последнюю очередь ассоциациям такого рода способствовала популярность у политических радикалов и идеалистов XIX-XX вв. макабрического афоризма М. Робеспьера: «Террор - это не что иное, как правосудие - незамедлительное, суровое и несгибаемое» (Herbst, 2003: 164).

Исторической особенностью французского революционного террора является его тесная связь с рационалистической традицией эпохи Просвещения. Это проявилось в идеологическом обосновании и соответствующем институциональном оформлении специфического типа якобинской политики. «Одним из элементов наследия Французской революции была идея, в соответствии с которой социальный мир - это мир социального изменения, а не застоя. Но если изменение является нормой и все человечество способно к рациональной мысли и действию, тогда вопрос состоит в направлении изменения, а также в том, каким образом справляться с реальным миром, где господствует социальный переворот, определяемый взаимоисключающими ценностными ориентациями» (Routledge Handbook, 2012: 106). В условиях национального и международного кризиса террор стал именно тем ответом, который якобинцы предложили своим противникам в виде реорганизации Революционного трибунала 5 сентября и декрета о «подозрительных» 17 сентября 1793 г. За образец был взят республиканский Рим эпохи гражданских войн, военных диктатур и сулланских проскрипционных списков.

Но даже на этом фоне российский опыт рассматривается некоторыми современными специалистами как исключительный. «Впервые в истории, - отмечает А. Гейфман, - экстремисты нового типа установили государственной контроль над Россией, страной, где современный терроризм пустил корни... Россия стала первой страной, которой когда-либо приходилось жить под пятой тотальной

${ }^{1}$ Статья подготовлена в развитие темы, начатой авторами в 2017 г. [В. Гуторов, А. Ширинянц, 2017]. 
идеологии, взятой на вооружение людьми, имевшими богатые террористические биографии и опыт» (Geifman, 2010: 122). Вместе с тем, как отмечает историк Дмитрий Шляпентох, диктаторский и террористический характер правления большевиков вселял в их противников надежду на то, что они вскоре потерпят крах, как и их предшественники-якобинцы (Shlapentokh, 1999: 96).

Методы террористической деятельности якобинцев и большевиков изучены в тысячах монографий и статей во всех подробностях как в историческом, так и в методологическом и сравнительном плане (см., например: Мельгунов, 1990; Mayer, 2000). Тем не менее, вплоть до наших дней остается еще немало вопросов, являющихся объектом напряженной теоретической дискуссии. Например, одна из особенностей российской традиции заключается в том, что многие явления и тенденции, характеризующие террористическую деятельность в иных регионах и культурах, принимали в России гипертрофированные формы и доводились до крайних пределов. Впрочем, подобные тенденции были свойственны и другим европейским странам, позднее вступившим на путь модернизации, например, Германии в период победы нацизма.

\section{ТРАДИЦИЯ РЕВОЛЮЦИОННОГО ТЕРРОРА В МАКРОСОЦИОЛОГИЧЕСКОМ ИЗМЕРЕНИИ}

В своей знаменитой работе «Русские мыслители» И. Берлин, характеризуя «психологию русского террора», акцентировал внимание, прежде всего, на национальных особенностях политического менталитета интеллигенции: «Однажды, пытаясь объяснить леди Оттолайн Моррелл русскую революцию, Бертран Рассел заметил, что большевистский деспотизм, каким бы ужасающим он ни был, по-видимому, является подходящим видом правления для России: “Если Вы спросите себя, как должны управляться характеры Достоевского, Вы [это] поймете". Взгляд, согласно которому деспотический социализм был вполне Россией заслужен, многими западными либералами был бы признан как довольно справедливый, по крайней мере, с учетом романа Достоевского о “бесах", [т.е.] радикальной российской интеллигенции. По степени собственной отчужденности от своего общества и своего воздействия на него, российская интеллигенция девятнадцатого века была феноменом почти sui generis. Ее идеологические вожди были небольшой группой, обладавшей сплоченностью и ощущением собственной миссии, свойственным религиозной секте. Своей неистовой моральной оппозицией существующему порядку, своей целеустремленной поглощенностью идеями, своей верой в разум и науку они проложили путь к русской революции и тем самым приобрели важную историческую значимость. Но все они слишком часто третировались английскими и американскими историками с характерной смесью снисхождения и морального отвращения. Причина состояла в том, что теории, которым они были столь горячо преданы, не были их собственными, они были заимствованы с Запада и поняты несовершенным образом. Потому что в своей фанатичной преданности идеологиям крайнего толка они одержимо рвались, как и бесы Достоевского, к слепому самоуничтожению, таща за собой 
свою страну, а впоследствии и весь остальной мир. Русская революция и ее последствия во многом усиливали убежденность, глубоко укоренившуюся в англосаксонской системе представлений: неистовый интерес к идеям является симптомом умственного и морального расстройства» (Berlin, 1978: XIII-XIV).

Напротив, Майкл Манн в работе «Темная сторона демократии» стремится объяснить особенности террора XX века не национальными особенностями, но, прежде всего, спецификой марксистской идеологии, а также логикой классовой борьбы и гражданских войн, побуждавших революционеров России, Китая и Камбоджи к радикализации политических программ. В процессе их реализации «создавались партийные государства, воплощавшие высокоидеологизированный и милитаристский социализм» (Манн, 2016: 561). Разработав «органическую концепцию народа не по этнической, а по классовой принадлежности», новая власть «взвинчивала революционный террор до последнего предела», практикуя политицид - уничтожение всех оппозиционно настроенных слоев общества, а затем и классицид - физическую ликвидацию всех «враждебных классов», противостоящих «пролетариату» (Манн, 2016: 562).

В своих беседах с Д.А. Холлом, опубликованных в 2011 г., М. Манн доказывал, что ценой «ужасных злодеяний», особенно сильно затронувших «крестьян в ходе принудительной коллективизации Сталина и Великого скачка Мао», сталинский и маоистский режимы в свое время не только доказали успешность моделей государственного социализма, но и «по крайней мере учились не совершать такого впредь, а Вьетнаму удалось достичь роста без массовых репрессий» (Манн, 2014: 28). Порочность советского авторитарного государства, созданного на основе террора, окончательно обнаружилась в эпоху перехода «из индустриальной фазы к постиндустриальной, когда централизованное государственное планирование выглядит уже не таким уместным» (Манн, 2014: 29).

Довольно близкий к методологии М. Манна способ анализа был еще раньше применен Баррингтоном Муром для характеристики французского революционного террора. «Опыт террора и в целом Французской революции, - отмечал он, - дал сильный импульс влиятельному течению западной политической мысли, которая отвергает любые формы политического насилия. Сегодня многие образованные люди, похоже, все еще считают террор демоническим выплеском массового насилия, неразборчивого в выборе жертв, а затем и выражением слепой ненависти и экстремизма, даже особой утопической ментальности, лежащей в основе тоталитаризма XX в. Я попытаюсь показать, что эта интерпретация искажена и карикатурна» (Мур, 2016: 102).

Основные аргументы, выдвинутые Муром для обоснования своей теоретической позиции, могут быть сведены к следующим принципиальным положениям: 1. Террор в революционной Франции проявлялся в двух основных формах - спонтанной (санкюлотской), ставшей импульсивным ответом на «невероятное обнищание людей» при старом порядке, постоянно порождавшем «трагическую меру бессмысленных смертей год за годом», и цееленаправленной, проявившейся в попытке Робеспьера и его сторонников подчинить народный порыв «некоторому рациональному и централизованному контролю», превратив террор в «эффективный инструмент политики»; 2. «Радикальная революция» и террор, отражая 
антикапиталистические настроения городской бедноты и крестьянства, продвигали вперед «буржуазную революцию», преодолевая попытки «консервативной части движения» остановить революционный процесс; 3. «Пожар революции, включая ее насильственные и радикальные аспекты», был во Франции неизбежен, поскольку «базовая социальная структура во Франции была фундаментально иной и поэтому исключала такой тип мирной трансформации, который Англия перенесла в XVIII-XIX вв.»; 4. Насилие и террор, сделав буржуазную революцию необратимой, хотя и внесли в дальнейшем элемент нестабильности в формирование политических институтов во Франции, «были в конечном счете благоприятными для развития парламентской демократии. Революция нанесла смертельную рану всему комплексу взаимосвязанных аристократических привилегий: монархии, земельной аристократии, сеньориальным правам, - комплексу, который конституировал существо старого режима. Она сделала это во имя частной собственности и равенства перед законом. Отрицать, что доминирующее направление и главные последствия революции были буржуазными и капиталистическими, значило бы заниматься тривиальной болтовней»; 5. Якобинский террор способствовал тому, что Франция, резко сократив временной период «догоняющего развития», в конечном итоге не только пошла по тому же пути, на который в разное время вступили Великобритания и США, но и смогла избежать итальянского и немецкого трагического опыта фашистских диктатур (Мур, 2016: $102,104,105,106-107,371)$.

Bce, приведенные выше, основные особенности и линии аргументации нашли отражение, а в некоторых случаях даже были значительно усилены, на различных этапах разработки И. Валлерстайном его концепции миросистемного анализа эволюции экономических и социально-политических структур в эпоху модерна. В частности, радикализм Французской революции и наполеоновских войн Валлерстайн рассматривает как последнюю попытку капиталистических сил, «которые базировались во Франции», «сломить надвигающуюся британскую гегемонию» на второй, «меркантилистской» стадии формирования современного мира-экономики (Валлерстайн, 2001: 47). Русская революция 1917 г. стала началом четвертой стадии. «Эта стадия, несомненно, должна была стать стадией революционных беспорядков, но она одновременно стала, парадоксально на первый взгляд, стадией консолидации мироэкономики промышленного капитализма» (Валлерстайн, 2001: 51). С конца XIX в. Россия в результате заметного проникновения иностранного капитала в промышленный сектор стала стремительно утрачивать статус полупериферийной страны, соскальзывая «К периферийному статусу». Радикальная революция и создание СССР, обеспечив народную поддержку пришедшей к власти «группе государственных управленцев», позволили стране в сжатые сроки не только восстановить «свое положение как очень сильного члена полупериферийного сообщества», но и «начать бороться за обретение полноправного статуса в сердцевине» (Там же). В этом плане СССР опередил Германию, потерпевшую поражение в Первой мировой войне и в дальнейшем уже в форме нацизма предпринявшей неудавшийся «отчаянный рывок», чтобы вновь «обрести уходящую из-под ног почву» и сравняться экономической и политической мощью с США и Великобританией (Валлерстайн, 2001: 51-52). 
Исходная позиция сравнительного анализа Валлерстайном опыта социальных трансформаций во Франции и России во многом совпадает с теорией М. Манна и вполне закономерно подводит к необходимости вновь оценить роль и значение революционного террора в принципиально различных исторических ситуациях. Подчеркивая, что сам факт использования террора не превращает Робеспьера в предтечу Ленина, а якобинцев - в агентов Коминтерна, Валлерстайн в основном разделяет позицию представителей школы «социальной интерпретации» (Д. Герен, Г. Руде и др.), настаивающих на «унитарном», т.е. буржуазном характере Французской революции, каковой она оставалась даже на пике якобинской диктатуры (Валлерстайн, 2016а: 134, 136-137). Тем самым он определенно отмежевывается от концепции Теды Скокпол, утверждавшей, «что Французская революция не была “буржуазной” и что она несопоставима с Английской революцией... В той же большей или меньшей степени, “что и любая буржуазная революция, это была бюрократическая, включающая массы и усиливающая государство революция", и в этом смысле уместно ее сравнение с Русской и Китайской революциями XX века» (Валлерстайн, 2016а: 61).

Эта концепция жестко противостоит так называемой «атлантической теории», сторонники которой рассматривают революцию во Франции как составную часть «единой революции Запада», которая «определяется атлантистами как “либеральная”, или “буржуазная” революция... Кроме того атлантисты обычно интерпретируют якобинскую фазу как "революционизирование революции” - революции, которая тем не менее была “радикальной с самого начала”», тем самым противопоставляя ее Русской революции, которую они рассматривают «как часть “незападной революции” ХХ века» (Валлерстайн, 2016а: 48-49)².

В целом И. Валлерстайн, в отличие от М. Манна и Б. Мура, не проявляет особого интереса к вопросу - какую роль играл революционный террор в конструировании «модерного государства, расположенного в рамках межгосударственной системы и ограниченного ею» (Валлерстайн, 2016b: 26). Однако он косвенно отвечает на данный вопрос, подчеркивая, что Французская революция и ее наполеоновское продолжение «выпустили джинна из бутылки» и «сделали идею народного суверенитета тем, с чем приходилось мириться любому правительству современного мира... К удивлению реставраторов глобального порядка, это была идея, которая укоренилась больше, чем они это осознавали: они не могли ее похоронить, как бы этого не хотели» (Там же). Поэтому «проблема для нотаблей заключалась в том, каким образом сконструировать некую структуру, которая будет казаться народной, а на самом деле не будет являться таковой, но тем не менее будет сохранять поддержку значительной части “народа”. Такая задача окажется непростой. Ее историческим решением и станет либеральное государство» (Валлерстайн, 2016b: 27).

${ }^{2}$ Следует в связи с этим отметить, что, например, Ф. Фукуяма, разделяющий основные позиции атлантической школы, тем не менее, в работе «Начала политического порядка» определяет период английской революции, последовавший за казнью короля Карла I в 1649 г. как «неудачный эксперимент с республиканским правительством», который вписывается в ту же логику «прогрессирующей радикализации», которая в разные эпохи была характерна для «французской, большевистской и китайской революций» (Fukuyama, 2011: 430). 
Однако исторический опыт явно свидетельствует о том, что в решении этой задачи либеральные государства постоянно сталкивались с серьезным противодействием и нередко терпели поражение. В 1920-1930-е гг. на большей части европейского континента - от России до Италии и стран Пиренейского полуострова - либеральные порядки были практически стерты с лица земли совместными усилиями левых и правых радикалов, установивших жесткие авторитарные и тоталитарные режимы в результате серии успешных политических революций. Сразу после окончания Второй мировой войны основные причины краха либеральной идеологии и политики были выявлены в знаменитом «анти-либеральном манифесте» «Человек науки против политики власти» (1946), написанном Г. Моргентау, создателем современной версии теории политического реализма (Morgenthau, 1967: 2-10, 42-50). «В рациональной общественной системе, - отмечал он, - нет места насилию. Поэтому для среднего класса жизненно важной (как в практическом, так и в интеллектуальном плане) становится проблема каким образом избегать вмешательства извне, в особенности - насильственного вмешательства, поскольку тончайший механизм социальной и экономической системы предполагает рациональность мира в самом широком смысле этого слова. Возвышая эту проблему до уровня абсолютно непогрешимого философского и политического постулата, либерализм упускал из виду как уникальность, так и совершенно исключительный характер того опыта, в рамках которого эта проблема возникла. Ведь отсутствие организованного насилия в течение длительных исторических периодов является скорее исключением, чем правилом во внутренних, но не в меньшей степени и в международных отношениях» (Morgenthau, 1967: 49).

В последующие десятилетия на передний план выступила тенденция антилиберальной мысли и критики, которая всегда развивалась параллельно вместе с самим либерализмом и практически никогда не прекращала своего существования. Одновременно все более явственными становились противоречия современного либерализма как в политическом, так и в этическом и культурном плане. «Другой глубокий парадокс современного либерального упорядочивания жизни, - отмечает Р. Бейнер, - состоит в том, что, усиливая в высшей степени ограниченное видение достоинства и уникальности индивида в рамках его или ее отдельной субгруппы, он одновременно предлагает коллективный образ жизни (“американизм”), который, быстро распространяясь, опутывает земной шар... Либерализм не в меньшей степени, чем социализм, феодализм или любой другой социальный порядок, - это глобальной устройство, т.е. образ жизни, который исключает другие образы жизни» (Beiner, 1995: VIII).

Самим же либералам некоторыми философами и политическими теоретиками XX в. нередко отводилась довольно одиозная роль «родоначальников» реакционных праворадикальных движений, включая национал-социализм и фашизм. «Либерализм, - писал Т.В. Адорно, - выпестовавший культуриндустрию, формы рефлексии которой навлекли на себя негодование жаргона подлинности, хотя и он сам является одной из них, был предтечей фашизма, который растоптал как своего прародителя, так и позднейших его сторонников» (Адорно, 2011: 58). 


\section{ТЕРРОРИЗМ И ЛЕВОРАДИКАЛЬНАЯ ФИЛОСОФИЯ}

Весьма примечательно, что создатели охарактеризованных выше макросоциологических теорий (как, впрочем, и их последователи), как правило, не стремились применить свои тщательно разработанные философские и общесоциологические схемы для анализа природы современного глобального террора и тех экономических и социально-политических институтов, которые в перспективе могут возникнуть в результате его использования определенными корпоративными силами. Первенство в этом отношении пока принадлежит леворадикальным альтернативным моделям, представленным, например, в имеющих явный оттенок социалистического утопизма концепциях «демократии множества» М. Хардта и А. Негри (Хардт, Негри, 2006: 133-433), «глобальной демократии» Р. М. Унгера (Unger, 1998; Unger, 2001; Unger, 2005) и др.

Исходный момент теоретической позиции западноевропейских и американских левых заключается в том, что большинство их идеологов не склонны считать, что процесс глобализации предопределяет исключительно однозначную конфигурацию политики, отвечающую интересам крупных корпораций и мировой олигархии. «Глобализация, - отмечает Роберто Мангабейра Унгер в работе "Что должны предложить левые?”, - теперь стала родовым алиби для капитуляции: каждая прогрессивная альтернатива высмеивается на том основании, что давление глобализации делает ее непрактичной. Истина, однако, заключается в том, что, как свидетельствует контрастный опыт современного Китая и Латинской Америки, даже настоящий глобальный экономический и политический порядок допускает широкий спектр эффективного ответа» (Unger, 2005: 133).

Интерес к классическому марксизму и неомарксистским идеям особенно возрос после глобального экономического кризиса 2008 г., когда «марксистские мыслители, политические активисты и экономисты - прежде высмеиваемые и игнорируемые - были перенесены из мусорной корзины истории прямо на главные телеканалы и их взглядами стали интересоваться» (Marxism and Education, 2011: 2).

Для таких радикалов неомарксистского толка как Майкл Хардт и Антонио Негри будущее будет определять сопротивление, в основе которого лежит «глубинное стремление к демократии - к настоящей демократии, то есть власти для всех, осуществляемой всеми, которая опиралась бы на равные и свободные взаимоотношения» (Хардт, Негри, 2006: 91; ср.: Unger, 2001: 474-480; Empire's New Clothes, 2004: 324-325). По убеждению левых идеологов, потенциал массового сопротивления способен преодолеть постоянно воспроизводимую современными масс-медиа «макабрическую манипуляцию словами», их систематическую дезинформацию и «ультра-изощренный терроризм», являющийся неизбежным «побочным фактором» ущерба, причиняемого «грабительскими войнами и завоеваниями», которые систематически выдаются за «благородные крестовые походы в поддержку свободы и демократии» (Boron, 2005: 7).

Сегодня такой прогноз, разумеется, вызывает множество ассоциаций и аналогий, начиная с принципов универсального гражданства, которые развивались ранними киниками и стоиками, анархистских утопических прозрений Прудона и молодого Маркса в его ранних рукописях, и заканчивая концепциями револю- 
ционного образования, «приобретенного в бою» и теоретически переработанного многочисленными последователями Э. Малапарте, Л. Троцкого, Р. Дебре и Э. Че Гевары, изучавшими диалектику «не по Гегелю» и готовыми пожертвовать собой и народом «в ядерной войне, чтобы его прах сцементировал новые общества» (Че Гевара) (Филатов, 2012).

Своеобразными пролегоменами к утопическим моделям и конструкциям М. Хардта, А. Негри и Р.М. Унгера вполне могут считаться образцы философского анализа современного терроризма в работах таких ярких теоретиков неомарксизма и идеологов современной левой как Терри Иглтон и Фредрик Джеймисон. «В любом случае, - отмечает Т. Иглтон в предисловии к книге “Святой террор”, - сам по себе терроризм не является политическим в некоем условном смысле этого термина и как таковой он бросает вызов обычным способам мысли левых. Левые чувствуют себя как дома, обсуждая имперскую власть и партизанскую войну, но они приходят в полное замешательство при мысли о смерти, зле, жертве и возвышенном. И все же, как я полагаю, эти и другие, родственные понятия вполне являются столь же подходящими для идеологии террора, как и более светские или материальные концепты» (Eagleton, 2005: VI).

Вместе с тем Иглтон признает, что терроризм как «современное изобретение» (modern invention) становится «политической идеей» в эпоху Французской революции и в итоге приходит к следующему, на первый взгляд, парадоксальному выводу, который, однако, в определенном смысле совпадает с идеями современных ученых относительно террористических аспектов политики современных либеральных государств: как политическое явление «терроризм и современное демократическое государство были близнецами от рождения. В эру Дантона и Робеспьера терроризм начал свою жизнь как государственный терроризм. Это было насилие, обрушенное государством на своих врагов, а не удар, наносимый суверенитету его безликими врагами... Закон нельзя разглядывать в его наготе, в противном случае он утратит свою власть вместе с собственными одеяниями. Именно это, как полагал Берк, является подлинным преступлением французских якобинцев: они сорвали с закона миловидные покровы господства и выставили на всеобщее обозрение его фаллическое варварство. Безнравственный вред Революции состоит не в ее скотской кровожадности и деспотизме, а в том, что она выболтала этот идеологический секрет» (Eagleton, 2005: 1, 50-51; см. подробнее: Cochet, 2008: 31).

Самым примечательным моментом этого размышления о природе революционного террора, на наш взгляд, является вполне осознанное, рациональное стремление политического философа левой ориентации усилить свою критическую позицию путем систематической апелляции к идеям убежденного консерватора Э. Берка. В истории политической мысли неоднократно встречались примеры глубокой, идущей от Прудона, леворадикальной критики якобинского терроризма (Kropotkine, 1909: 712-720). Но слияние в политико-философском пространстве левых и консервативных идей и теорий - явление сравнительно новое, впервые обозначившееся на рубеже XIX-XX вв. в эпоху первого глобального кризиса идейных оснований европейской культуры, накануне и после Первой мировой войны весьма отчетливо проявившее себя в Италии и Германии, 
а в дальнейшем во второй половине XX века получившее новое развитие в различных версиях синтеза ведущих западных идеологий.

Одним из побочных следствий такого синтеза являются систематические попытки активного использования левыми политическими философами методологии гуманитарных наук и паранаучных доводов для анализа сложных современных процессов и явлений, в том числе и международного терроризма. Так, например, Ф. Джеймисон, отмечая в книге «Идеологии теории», что в разработанной теоретиками Франкфуртской школы концепции «тотальной системы» зафиксирована на философском уровне вполне реальная тенденция трансформации современного мира в замкнутую, «безшовную» сеть, объединившую «медиа-технологии, мульти-национальные корпорации и международный бюрократический контроль», делает следующий вывод: эта концепция, по существу, не только поощряет «возрождение анархистской оппозиции марксизму», но и может служить «как оправдание для терроризма» (Jameson, 2008: 444; см. также: 509).

Если признать, что в идеях философов Франкфуртской школы содержится зерно истины, такая ситуация, подчеркивает Джеймисон в другой своей работе «Валентности диалектики», «возвращает нас к чему-то вроде хантингтоновской мировой политики с той лишь оговоркой, что единственной “религией” или “религиозной традицией”, которая, по всей видимости, действительно демонстрирует энергию сопротивления глобализации или вестернизации (“вестоксификации”, как ее называют иранцы), как вполне можно предположить, является ислам. После исчезновения международного коммунистического движения стало казаться, что на мировой сцене только определенные течения внутри ислама, характеризуемые в целом как “фундаменталистские”, реально позиционируют себя в форме оппозиционной программы, противостоящей западной культуре, или, вернее, западному “культурному империализму”» (Jameson, 2009: 471).

Конечно, трудно допустить, чтобы мыслитель такого уровня как Джеймисон не отдавал себе отчета в том, что его попытка обвинить философов Франкфуртской школы в «поощрении терроризма» и признание им исламских фундаменталистов преемниками В.И. Ленина, Г. Поллита, У. Галлахера, Г. Димитрова и П. Тольятти легко могут спровоцировать ответные обвинения со стороны его оппонентов в «контрпровокации» и отнюдь не виртуальном идеологическом потворстве современному исламистскому терроризму, а также его тайным и явным покровителям. Скорее всего, подобно многим чистым теоретикам, он просто считает допустимыми любые доводы и аргументы, если они эффективно способствуют защите определенной, рационально выверенной линии аргументации в глобальной философско-политической дискуссии (см. подробнеe: Nancy, 1997).

$$
* * *
$$

Весьма характерно, что большинство объяснительных моделей, анализ которых представлен в статье, исходят, как любили говорить немецкие ученые в прошлом веке, von großen Voraussetzungen (из больших предпосылок), ограничиваясь при этом лишь «подведением итогов» террористической политики партий и госу- 
дарств в XVIII-XX вв. Различные аспекты дискуссии вокруг самого феномена терроризма и роли государства в его сдерживании или, наоборот, распространении затрагиваются в них лишь косвенно, поскольку террор как таковой нивелирован до уровня сегмента (более или менее существенного) макропроцессов и структур, определяющих эволюцию к индустриальному и постиндустриальному типу общества. Независимо от того, содержится ли в этих моделях осуждение революционного насилия или же оно оценивается положительно и нейтрально, характер и уровень анализа довольно резко контрастирует с работами ученых, специализирующихся непосредственно в области изучения современного терроризма и его истоков [см.: Терроризм, 2015]. При этом историческая линия преемственности между различными этапами эволюции самой политической традиции террора трактуется в макромоделях весьма абстрактно и нередко становится едва различимой.

Полезный эффект охарактеризованных выше макросоцилогических теорий проявляется, в частности, в дополнительном теоретическом обосновании традиционного для классического марксизма и либеральной теории историософского вывода об амбивалентной роли революции, террора и насилия в формировании институтов либеральной демократии и в таких «классических» странах, как США, Великобритания и Франция, и в странах, позднее вступивших на путь модернизации и переживших по этой причине негативный опыт авторитарных и тоталитарных диктатур (Италия, Германия, Россия, страны Центральной и Восточной Европы, коммунистический Китай и др.).

Радикальные аналитические идеи Джеймисона, на наш взгляд, также свидетельствуют о том, что неомарксистские идеологи в своем анализе современного терроризма, в определенном плане, остаются столь же приверженными абстрактным философским конструкциям, как и ученые, ориентирующиеся на охарактеризованные выше макро-теоретические парадигмы современной социологии и академического марксизма со всеми свойственными им несомненными преимуществами и неизбежными аберрациями (ср.: Hobsbawm, 1995: 335-347). Так, критикуя широко известную работу Д. Кина «Размышления о насилии», Ч. эльОджейли вполне справедливо отмечал: «Насилие для Кина может быть благим, если оно усиливает или создает плюралистическое, ненасильственное гражданское общество, когда оно, в конечном счете, служит тому, чтобы уменьшить или устранить насилие. Но это суждение представляет собой в буквальном смысле разновидность апологетики, распространенной у революционеров, к которым Кин, без сомнения, относится враждебно. Такая враждебность, начиная с 1960-х гг. вполне соответствовала всеобщему отходу от идеи революции, которая во все возрастающей степени ассоциировалась с насилием, террором, тоталитаризмом» (el-Ojeili, 2012: 150-151; Keane, 1996: 91; Keane, 2004: 42-69; cp.: Bellinger, 2001: 113-134).

Подобная ситуация, сложившая в гуманитарных науках и политической философии, конечно, не должна настраивать ученых исключительно на пессимистический лад, поскольку ее преодоление зависит, в конечном счете, не от науки как таковой, но прежде всего, от сферы практической политики, объединяющей усилия всех государств, направленные на защиту принципов международного 
права. Именно эффективностью этих усилий будет определяться окончательная победа в борьбе с одним из самых одиозных видов зла в современном мире.

\section{БИБЛИОГРАФИЯ}

Адорно Т. В. (2011), Жаргон подлинности. О немеикой идеологии, Москва.

Валлерстайн И. (2001), Анализ мировых систем и ситуация в современном мире, СанктПетербург.

Валлерстайн И. (2016а), Мир-система Модерна, Том III: Вторая эпоха великой экспансии капиталистического мира-экономики, 1730-1840-е годы, Москва.

Валлерстайн И. (2016b), Мир-система Модерна, Том IV: Триумф иентристского либерализма, 1789-1914, Москва.

Гуторов В., Ширинянц А. (2017), Терроризм как политический и исторический феномен: современные проблемы интерпретации, «Przegląd Strategiczny» № 10, pp. 275-296.

Манн М. (2014), Власть в XXI столетии: беседы с Джоном А. Холлом, Москва.

Манн М. (2016), Темная сторона демократии: Объяснение этнических чисток, Издательство «Пятый Рим» (ООО «Бестселлер»), Москва.

Мельгунов С. П. (1990), Красный террор в России. 1918-1923. Москва.

Мур Б. (2016), Социальные истоки диктатуры и демократии: Роль помещика и крестьянина в создании современного мира, Москва.

Терроризм как сочиально-политическое явление. Противодействие в современных условиях (2015), (ред.) В. Ю. Бельский, А. И. Сацута, Москва.

Филатов С. (2012), Карибский кризис. Взгляд с высоты полувека, http://interaffairs.ru/read. php?item=8832 (11.02.2018).

Хардт М., Негри А. (2006), Множество: война и демократия в эпоху империи, Москва.

Beiner R. (1995), What's the Matter with Liberalism?, Berkeley-Los Angeles-Oxford.

Bellinger Ch. K. (2001), The Genealogy of Violence, Oxford.

Berlin I. (1978), Russian Thinkers, London.

Boron A. A. (2005), Empire and Imperialism. A Critical Reading of Michael Hardt and Antonio Negri, London-New York.

Cochet F. (2008), Democracies and the Ethics of War: The Record of the Past, in: Democracies at War against Terrorism. A Comparative Perspectives, (ed.) S. Cohen, New York.

Eagleton T. (2005), Holy Terror, Oxford-New York.

el-Ojeili Ch. (2012), Politics, Social Theory, Utopia and the World-System. Arguments in Political Sociology, Palgrave Macmillan, New York.

Empire's New Clothes. Reading Hardt and Negri (2004), (eds.) P. A. Passavant, J. Dean, New YorkLondon.

Fukuyama F. (2011), The Origins of Political Order. From Prehuman Times to the French Revolution, New York.

Geifman A. (2010), Death Orders. The Vanguard of Modern Terrorism in Revolutionary Russia, Santa Barbara, California-Denver, Colorado-Oxford.

Herbst Ph. (2003), Talking Terrorism: A Dictionary of the Loaded Language of Political Violence, Westport, Connecticut-London.

Hobsbawm E. (1995), Age of Extremes. The Short Twentieth Century, London. 
Jameson F. (2008), The Ideologies of Theory, London-NewYork.

Jameson F. (2009), Valences of the Dialectic, London-NewYork.

Keane J. (1996), Reflections on Violence, London.

Keane J. (2004), Violence and Democracy, Cambridge.

Kropotkine P. (1909), La grande Revolution. 1789-1793, Paris.

Marxism and Education. Renewing the Dialogue, Pedagogy, and Culture (2011), (ed.) P. E. Jones, New York.

Mayer A. J. (2000), The Furies. Violence and Terror in French and Russian Revolutions, Princeton, New Jersey.

Morgenthau H. J. (1967), Scientific Man versus Power Politics, Chicago-London.

Nancy J.-L. (1997), Sense of the World, Minneapolis-London.

Routledge Handbook of World-System Analysis (2012), (eds.) S. J. Babones, Chr. Chase-Dunn, London-New York.

Shlapentokh D. (1999), The Counter-Revolution in Revolution. Images of Thermidor and Napoleon at the Time of Russian Revolution and Civil War, Houndmills-London.

Unger R. M. (1998), Democracy Realized. The Progressive Alternative, London-New York.

Unger R. M. (2001), False Necessity. Anti-Necessitarian Social Theory in the Service of Radical Democracy, London-New York.

Unger R. M. (2005), What Should the Left Propose?, London-New York.

\begin{abstract}
АННОТАЦИЯ
Статья посвящена актуальным проблемам теоретического анализа революционного терроризма эпохи модерна. Характеризуются специфические особенности революционного терроризма в плане сравнения исторического опыта Великой французской и Октябрьской революций. Критически оцениваются результаты интерпретации этого опыта в общесоциологических теориях М. Манна, Б. Мура и И. Валлерстайна, а также в политической философии неомарксизма (М. Хардт, А. Негри, Р. М. Унгер, Т. Иглтон, Ф. Джеймисон). В статье отмечается, что большинство объяснительных макросоциологических моделей ограничиваются лишь «подведением итогов» террористической политики партий и государств в XVIII-XX вв. Различные аспекты дискуссии вокруг самого феномена терроризма и роли государства в его сдерживании или, наоборот, распространении затрагиваются в них лишь косвенно, поскольку террор как таковой нивелирован до уровня сегмента (более или менее существенного) макропроцессов и структур, определяющих эволюцию к индустриальному и постиндустриальному типу общества. При этом историческая линия преемственности между различными этапами эволюции самой политической традиции террора трактуется в макромоделях весьма абстрактно и нередко становится едва различимой. Аналитические идеи философии современного левого радикализма также свидетельствуют о том, что неомарксистские идеологи в своем анализе современного терроризма, в определенном плане, остаются столь же приверженными абстрактным философским конструкциям, как и ученые, ориентирующиеся на макро-теоретические парадигмы современной социологии и академического марксизма со всеми свойственными им несомненными преимуществами и неизбежными аберрациями.
\end{abstract}




\title{
TERRORISM AND REVOLUTION
}

\begin{abstract}
The article is devoted to actual problems of the theoretical analysis of the revolutionary terrorism of the modern era. The paper considers the specific features of revolutionary terrorism in frames of a comparison of the historical experience of the French and Russian October Revolutions. In the course of a comparative analysis the authors assess critically the results of the interpretation of this experience in the general sociological theories of Michael Mann, Barrington Moore and Immanuel Wallerstein and political philosophy of Neo-Marxism (Michael Hardt, Antonio Negri, Roberto Mangabeira Unger, Terry Eagleton, Fredric Jameson). The article notes that the majority of explanatory macro-sociological models are limited to the «summing up» of the terrorist policy of the parties and States in the XVIII-XX centuries. The various aspects of the discussion around the very phenomenon of terrorism and the role of the state in its containment or, on the contrary, distribution are affected only indirectly, as the terror itself is reduced to the segment level of macro-processes and structures (more or less significant) that determine the evolution to an industrial and post-industrial type of society. The historical line of continuity between the different stages of the evolution of the political tradition of terror is treated in the macro-models very abstractly and often becomes barely visible. Analytical ideas of the philosophy of modern left-wing radicalism also suggest that the neo-Marxist ideologues in their analysis of modern terrorism are equally committed, in a certain respect, to the abstract philosophical constructs, as well as the scientists oriented to macro-theoretical paradigms of modern sociology and academic Marxism with all their characteristic undoubted advantages and unavoidable aberrations.
\end{abstract}

Keywords: terrorism, revolution 
